\title{
?1
}

TI 2019-015/VIII

Tinbergen Institute Discussion Paper

\section{The Global Macroeconomics of a Trade War: The EAGLE model on the US-China trade conflict}

Wilko Bolt ${ }^{1,2}$

Kostas Mavromatis ${ }^{1,3}$

Sweder van Wijnbergen ${ }^{1,3}$

${ }^{1}$ The Nederlandsche Bank

2 Vrije Universiteit Amsterdam

3 University of Amsterdam 
Tinbergen Institute is the graduate school and research institute in economics of Erasmus University Rotterdam, the University of Amsterdam and VU University Amsterdam.

Contact: discussionpapers@tinbergen.nl

More TI discussion papers can be downloaded at https://www.tinbergen.nl

Tinbergen Institute has two locations:

Tinbergen Institute Amsterdam

Gustav Mahlerplein 117

1082 MS Amsterdam

The Netherlands

Tel.: +31(0)205984580

Tinbergen Institute Rotterdam

Burg. Oudlaan 50

3062 PA Rotterdam

The Netherlands

Tel.: +31(0)10408 8900 


\title{
The Global Macroeconomics of a Trade War: The EAGLE model on the US-China trade conflict*
}

\author{
Wilko Bolt ${ }^{\dagger}$ \\ Kostas Mavromatis \\ Sweder van Wijnbergen ${ }^{\S}$
}

January 29, 2019

\begin{abstract}
We study the global macroeconomic effects of tariffs using a multiregional, general equilibrium model, EAGLE, that we extend by introducing US tariffs against Chinese imports into the US, and subsequently Chinese tariffs against US imports into China, consistent with recent trade policies by the US and the Chinese governments. We abstract from tariffs on goods exported from the euro area, focusing on a US-China trade war. A unilateral tariff from the US against China dampens US exports in line with the Lerner Symmetry theorem but global output contracts. Global output contracts even further after China retaliates. The euro area benefits from this trade war. These European trade diversion benefits are caused by cheaper imports from China and improved competitiveness in the US. As price stickiness in the export sector in each region increases, the negative effects of tariffs in the US and China are mitigated, but the positive effects in the euro area are then also dampened.
\end{abstract}

JEL Classification: E32, F30, H22

Keywords: Trade Policy, Exchange Rates, Trade Diversion, Local Currency Pricing

\footnotetext{
*This paper represents the views of the authors and not necessarily those of De Nederlandsche Bank or the Eurosystem. We have greatly benefited from comments by Peter van Els, Jakob de Haan, Pascal Jacquinot, Massimiliano Pisani and Johan Verbruggen.

${ }^{\dagger}$ De Nederlandsche Bank and Free University, Amsterdam, w.bolt@dnb.nl

${ }^{\ddagger}$ De Nederlandsche Bank and University of Amsterdam, k.mavromatis@dnb.nl

${ }^{\S}$ De Nederlandsche Bank, University of Amsterdam, Tinbergen Institute and CEPR, $\mathrm{s} \cdot \mathrm{j} \cdot \mathrm{g} \cdot$ vanwijnbergen@uva.nl
} 


\section{Introduction}

After a decades long gradual move towards free trade, United States (US) president Trump has recently shaken the foundations of the global trading system by imposing steep tariffs on imports from China and other countries. As the US-China trade conflict continues to deepen, there is widespread concern that an escalating trade war between the two largest world economies may derail the recovery from the Great Financial Crisis (GFC). An analysis of the likely macroeconomic effects of a trade war should thus be of substantial interest. In this paper, we extend the European Central Bank (ECB)'s global multiregional EAGLE model by including trade tariffs on bilateral trade flows and use this new version of the EAGLE model to trace the macroeconomic impact of a trade war between the US and China. 1

In January 2018, the US placed a 30\% tariff on foreign solar panels, to be reduced to $15 \%$ after four years. China, the world leader in solar panel manufacture, decried the tariffs. This signaled the start of the trade conflict between the US and China. While the overall volume of trade covered so far remains limited - new import tariffs implemented by the US, China, Canada, Mexico and the European Union (EU) accounted for about 3\% of global imports in September 2018 - additional measures are threatened at the time of writing this paper. Following China's decision to retaliate against US tariffs on Chinese goods, the US announced additional tariffs during the summer covering USD 200 billion of imports from China. These additional measures were implemented in September 2018, but tariffs as high as $25 \%$ on all US imports from China have been threatened in the verbal exchanges that are part of this ongoing trade war. New protectionist measures have also be threatened at times by the US administration against all imports of automobiles and auto parts, raising the risk of a geographical spread of the trade war which could escalate further as additional regions directly affected — like Europe — would start retaliating also. There can be little doubt that a trade war this extensive will have serious macroeconomic consequences.

However, the literature on trade tariffs provides little guidance on macroeconomic effects of tariffs; the bulk of it is in the domain of the theory of international trade, abstracting from macroeconomic considerations. An early exception is Van Wijnbergen (1987) who provides a theoretical intertemporal analysis of the employment and current account effects of trade tariffs under various assumptions about real wage indexation in a small open economy setting, but no attempt at quantification. More recent papers use more applied quantitative models and computer simulation instead of theoretical analysis. An example is Linde and Pescatori (2017) who use a quantitative DSGE model to analyze Lerner symmetry, the equivalence between import tariffs and export taxes

\footnotetext{
${ }^{1}$ See Gomes et al. (2012) for a very detailed description of the EAGLE model structure.
} 
— a stalwart of trade theory (Lerner (1936), Helpman and Krugman (1989)). However, their use of a two country model precludes an analysis of one of the key issues we are interested in, third party effects of a bilateral trade war: if China and the US engage in a tit-for-tat tariff war, what will the implications be for Europe, assuming it can stay out of the conflict? Such an analysis should of course take into account the traditional analysis of the impact of trade tariffs on trade flows, focusing on trade destruction and trade diversion in a multicountry world. But such important distortions of relative prices are likely to have an impact on macro aggregates too: on employment, overall growth, investment and intertemporal variables like the trade balance/current account and that is what we provide in this paper.

To do this, we use the multiregional, general equilibrium EAGLE (Euro Area and Global Economy) model:2 This model encompasses the entire world economy and explicitly models bilateral trade flows and their relative prices for each region, including exchange rates. Imposing trade tariffs triggers many moving parts across economies. Falling employment dampens household consumption; there are complex real interest rate effects of gradual relative price changes as firms gradually reset prices in response to actual and/or anticipated tariff changes. Lower economic activity depresses investment and exports suffer from an appreciating exchange rate.

When all the dust has settled, we find that the US and China lose substantially and for a long time in terms of lower GDP but that the euro area (EA) may actually benefit as trade flows are diverted to the one player that by assumption of our simulations stays out of the trade war itself and is not dragged in by others. EA competitiveness increases relative to the US and China and it gets access to cheaper imports from regions whose exports are blocked from other regions and therefore export to Europe instead. However, the benefits are not large enough to reverse the overall negative impact of the US-China trade war on global output and employment for a substantial number of years.

The paper is organized as follows. In section 2, we present our literature review. In section 3, we present our extension of the EAGLE model with Tariffs, in section 4 we present our results. We conclude in section 5 .

\footnotetext{
${ }^{2}$ In fact there is a family of EAGLE models with each model specific to a particular country in the euro area (EA). Actors in the models are the US, the specific country setting up an EAGLE variant, the rest of the euro area (REA) except that country, and the rest of the world (RoW). We use De Nederlandsche Bank (DNB) variant, with the Netherlands as the specific EA country lifted out of the aggregate EA.
} 


\section{Related literature}

The gradual move towards free trade - hand in hand with rapid trade growth in the past decades - led to a body of theoretical and empirical research that largely focused on international trade flows and terms-of-trade effects. In a recent joint report by the IMF, World Bank and WTO (2017) the general view widely shared among academic economists is repeated, that trade liberalization and openness has brought about higher productivity, greater competition, lower prices, and improved living standards. Recent turmoil has focused attention on potentially negative effects on particular sectors or groups in society and rekindled an interest in Trade Adjustment Measures: see for example Department of Labor (2018) for a description of the US Trade Adjustment Assistance program. But even that debate remains at a sectoral level. The post-crisis uptick in protectionism and rising anti-trade and anti-globalization sentiment associated with a slowdown in trade flows are, however, changing the discussion towards the macroeconomic impact of trade conflicts. Macro consequences are paramount: the US recent foray into more aggressive trade policy is, at least as seen from the outside, largely driven by concerns about the trade balance, which is a quintessential macroeconomic factor. Moreover, there is a growing concern that the US-China trade war may dampen world output and global trade. But at the same time, some third party countries may profit from trade diversion effects of a trade war between two countries or groups of countries.

The early trade literature already discussed the motives behind and economic impact of trade wars. The traditional view is that a country can reap terms-of-trade gains by raising tariffs as long as its trading partners will not retaliate: the "optimal tariff" argument, see Johnson (1951) for a very early contribution. This argument is supported

by the very ambitious recent empirical analysis undertaken by Ossa (2014). Caliendo and Parro (2015) give a dissenting view: they show that the optimal tariff may in fact be negative once production linkages and intermediate goods are taken into account. The seminal work of Johnson (1953) first analyzed the 'beggar-thy-neighbor' incentives to increase trade tariffs but showed that in a trade war a country can actually gain by imposing an optimal tariff even when others retaliate. Ossa (2014) disagrees and argues there will be substantial global and individual country losses in a full-scale tariff war with retaliation. Kutlina-Dimitrova and Lakatos (2017) report similar (although substantially smaller) losses, admittedly in scenario's that are also less extreme than the ones played out in Ossa (2014). But this part of the literature, interesting as it is, abstracts from macroeconomic effects like the impact of a trade war on output, employment, or intertemporal trade positions (i.e. trade balances), the key areas of interest in our paper. 
An early paper on macroeconomic effects of trade tariffs is Van Wijnbergen (1987), who provides a theoretical analysis of the employment and current account impact of trade tariffs in a simple two period small open economy model under various assumptions about real wage indexation and about whether tariffs are temporary or permanent. This analysis is extended to a general equilibrium setting in Van Wijnbergen (2018), but neither paper gives quantitative assessments like we do in this paper.

Linde and Pescatori (2017) do present a global quantitative model, focusing on the robustness of the well known Lerner symmetry result in a large-scale two region DSGE model with a variety of macroeconomic frictions included, although the global market clearing mechanisms are not entirely clear from the exposition provided ${ }^{3}$ Additionally, they quantify the macroeconomic costs of a trade war and also find that those costs can be substantial, with permanently lower income and trade volumes. Erceg et al. (2018) explore various tax equivalences to tariff policy within the context of a small open economy New-Keynesian model. We add to this literature by analyzing the macroeconomic effects of tariffs and retaliatory action within a global general equilibrium framework incorporating short-run macroeconomic frictions, but add focus on third party effects. ${ }^{4}$ What would be the impact on the EA if the US and China engage in rounds of retaliatory tariffs against each other?

A number of policy institutions have simulated different scenarios to gauge the economic effects of trade conflicts, using a variety of models and assumptions The results have - at the time of writing of this article - only been released in publications aiming at the general public, so a comparison of methodology, specific policies simulated, model structures or results cannot readily be made. Suffice it to say that the predicted effects are largely of similar magnitude although typically other channels to those we consider in this paper have been added to the tariff measures themselves, such as (exogenously imposed) confidence or volatility shocks, making a comparison difficult. But considering that these additional effects play a role while the overall impact seems largely similar, it seems safe to conclude that our analysis predicts a larger macroeconomic impact from the trade policies themselves without considering these additional channels.

\footnotetext{
${ }^{3}$ There is mention of a liquidity trap, but no discussion of a zero lower bound (ZLB) and what if the ZLB hits, is the equilibrating mechanism that ensures a zero global current account.

${ }^{4}$ Cf. Caliendo and Parro (2015) for an analysis of third party effects in an applied trade theory analysis of NAFTA.

${ }^{5}$ See e.g. Bank de France (2018), De Nederlandsche Bank (2018), ECB (2018), IMF (2018) and OECD (2018).
} 


\section{The EAGLE model with trade Tariffs}

\subsection{The EAGLE model}

The EAGLE model is an open economy DSGE that accounts for international macroeconomic interdependence, developed by Gomes et al. (2012). It is a large-scale microfounded model that explicitly specifies the behavior of households, firms and monetary and fiscal authorities. The model contains 4 regions: the home country (Netherlands), the rest of the euro area (REA), US and the Rest of the World (RoW). Since we are interested in a trade war between the US on the one hand and the non-EU RoW on the other, we take RoW as representing China, (and Mexico, Canada and other non-EU targets of the US trade offensive). In what follows, we only sketch the EAGLE model's structure to describe our extensions and to the extent necessary to follow this paper a full description can be found in Gomes et al. (2012).

Consider first the consumption side of the model: in EAGLE there are two types of consumers: 'Ricardian' (type $I$ ) and 'non-Ricardian' (type $J$ ). Ricardian consumers buy and sell domestic government bonds and internationally traded US bonds, accumulate physical capital and rent its services to domestic firms and hold money for transaction purposes. Non-Ricardian consumers are by assumption excluded from financial and capital markets and intertemporally smooth their consumption only to the extent they can do that by adjusting their holdings of money.

On the production side, the model features final and intermediate goods. Firms producing intermediate goods are split into firms producing tradables and firms producing non-tradables. Both kinds of firms combine physical capital and labor to produce their goods and set their price infrequently, thereby creating price stickiness in the model. Final good firms operate under perfect competition and produce either consumption or investment goods which are traded domestically only. To produce their goods the final goods firms combine intermediate tradables and non-tradables using a CES production technology. The tradables used in final goods production are themselves a combined product of intermediate traded goods produced at home and intermediate traded goods produced abroad. The foreign and domestically produced traded goods are themselves aggregated into the higher level traded good using a CES production technology (see figure 10 in the Annex for a goods-price flow diagram).

Finally, monetary authorities in the different regions set the nominal interest rate according to a Taylor rule targeting domestic inflation rate, output growth rate and, in the case of China (by assumption) the (nominal or real) exchange rate. Fiscal policy is conducted by the fiscal authorities of each country individually (region specific). Each authority sets public expenditure for purchases that are fully biased towards 
non-tradable goods and lump-sum transfers. Public expenditure is financed by raising lump-sum or distortionary taxes, or by issuing bonds in the domestic financial markets and by paying taxes later, all subject to an intertemporal budget constraint.

\subsection{Tariffs introduced in the EAGLE model}

Consider now the extension of the EAGLE model to incorporate trade tariffs. As we mentioned in the short description of the model above, final goods firms operate in a perfectly competitive environment. Firms producing tradable and nontradable intermediate goods instead are monopolistically competitive and set their prices in a staggered manner a la Calvo (1983). The same assumptions hold for firms producing intermediate tradable goods. However, these firms sell their goods both domestically and abroad. In the EAGLE model, imperfect pass through is assumed which implies local currency pricing. That is, each tradable good firm charges a different price for its good according to the destination country. Since the EAGLE model features four regions, this means that each tradable good firm sets four different prices for its good, each conditional on the destination market. We rule out arbitrage driven re-exporting. In this section, we focus on the profit maximization problem of the representative firm in the tradables sector.

In the model, setting a tariff on imports translates to imposing a distortionary tax on exporters. Note that the model does not feature a distribution sector. The tariff thus is imposed directly upon the producer (exporter). Given the downward sloping demand curve and the upward sloping supply curve that monopolistically competitive firms face, the eventual tax burden will be shared between the consumer and the producer, once all firms have repriced their output in the various export markets. A higher elasticity of substitution between product varieties implies less market power; then exporters bear most of the tax burden and vice versa. Each government rebates its tariff revenues to households through lump-sum transfers. Since this is a general equilibrium model, the outcomes display Lerner-symmetry: import tariffs are eventually equivalent to export taxes, higher tariffs lead to both lower imports but equally also to lower exports. The trade balance response depends on what happens to intertemporal variables (real interest rates, gradual changes in the real exchange rate, possibly phasing out of tariffs) as well as on potential trade diversion.

Price setting in the tradable goods sector Given local currency pricing, monopolistically competitive tradable goods firms charge different prices in local currency at home and in each foreign region. Pricing in the domestic market is standard. The firm sets the price of its differentiated product infrequently, à la Calvo (1983) in order to maximize the expected discounted sum of its profits. 
Price setting in the export market Firm $h$ in the home country, $H$, discriminates across countries, by invoicing and setting the price of its brand in the currency of the generic destination country $C O$. As mentioned above, each firm sets the price of its good in a staggered manner, à la Calvo (1983). In particular, each firm re-optimizes its prices in a given period $t$ with probability $1-\xi_{\chi}\left(0 \leq \xi_{\chi} \leq 1\right)$. All firms that are called upon re-optimizing set the same export price, $\tilde{P}_{X, t}^{H, C O}$, while those which do not re-optimize update their prices according to the following scheme:

$$
P_{X, t}^{H, C O}(h)=\left(\Pi_{X, t-1}^{H, C O}\right)^{\chi_{X}} \bar{\Pi}^{1-\chi_{X}} P_{X, t-1}^{H, C O}(h)
$$

where $\Pi_{X, t-1}^{H, C O} \equiv P_{X, t-1}^{H, C O} / P_{X, t-2}^{H, C O}$ is the sector specific inflation rate and the foreign inflation objective is assumed to be time invariant and equal to the Home long-run inflation objective $\bar{\Pi}^{C O}=\bar{\Pi}$. Parameter $\chi_{X}$ denotes the degree of indexation to past inflation. For consistency, we have kept the notation exactly the same as in the original paper by Gomes et al. (2012).

Each exporting firm may be subject to tariffs by the government of the destination country. Instead of assuming that tariffs are imposed after the goods are transported and, hence, to the consumer directly as in Linde and Pescatori (2017), we assume that tariffs are imposed on exporters while they set their prices, in the spirit of Farhi et al. (2014). This way, the final price imposed by the exporter incorporates the tariff. Each exporting firm that re-optimizes thus sets its price in order to maximize the expected discounted sum of its profits. The expected discounted sum of profits expressed in domestic currency receives the following form:

$E_{t}\left[\sum_{k=0}^{\infty} \Lambda_{I, t+k}\left[\sum_{C O \neq H}\left(\left(\xi_{X}\right)^{k}\left(\frac{S_{t+k}^{H, C O} P_{X, t+k}^{H, C O}(h) I M_{t+k}^{C O}(h)}{1+\tau_{t+k}^{C O, T}}-M C_{t+k}^{H}\left(I M_{t+k}^{C O}(h)+\psi_{T}\right)\right)\right)\right]\right]$

subject to price indexation scheme (11) and taking as given the demand function of the importing country:

$$
I M_{t+k}^{C O}(h)=\left(\frac{P_{X, t+k}^{H, C O}(h)}{P_{X, t+k}^{H, C O}}\right)^{-\theta_{T}} I M_{t+k}^{C O, H}
$$

where $P_{X, t}^{H, C O}$ is the cost minimizing price of one unit of the tradable basket defined as: 


$$
P_{X, t}^{H, C O}=\left[\frac{1}{s^{H}} \int_{0}^{s^{H}} P_{X, t+k}^{H, C O}(h) d h\right]^{\frac{1}{1-\theta_{T}}}
$$

where $s^{H}$ denotes the size of the home country, $H$. Parameter $\theta_{T}$ represents the intratemporal elasticity of substitution across varieties. In the equations above, $\Lambda_{I, t+k}$ denotes the stochastic discount factor of households of type $I$ in the home country $H \square^{6}$ $S_{t}^{H, C O}$ denotes the nominal exchange rate between the home country $H$ and country $C O$, defined as the domestic currency price of the foreign currency, $P_{X, t}^{H, C O}(h)$ denotes the price of variety $h$ set optimally in country $C O$ by the home tradable firm $h, \tau_{t}^{C O, T}$ denotes the Tariff imposed on home firm $h$ by the government of the destination country $C O, I M_{t}^{C O}(h)$ denotes the demand of country $C O$ for variety $h$, while $I M_{t}^{C O, H}$ is the total demand of country $C O$ for goods produced in the home country $H . M C_{t}^{H}$ in equation (2) is the nominal marginal cost which is identical across firms within each sector. Parameter $\psi_{T}$ in the same equation represents fixed costs taking the same values across firms belonging to the same sector. The first order condition at time $t$ with respect to $\tilde{P}_{X, t}^{H, C O}$ is as follows:

$$
\begin{aligned}
& E_{t}\left[\sum_{k=0}^{\infty}\left(\xi_{X}\right)^{k} \Lambda_{I, t+k}\left(\prod_{s=1}^{k}\left(\Pi_{X, t+s-1}^{H, C O}\right)^{\chi X} \bar{\Pi}^{1-\chi_{X}} \frac{\tilde{P}_{X, t}^{H, C O}}{1+\tau_{t+k}^{C O, T}}-\frac{\theta_{T}}{\theta_{T}-1}\left(S_{t+k}^{H, C O}\right)^{-1} M C_{t+k}^{H}\right) I M_{t+k}^{C O}(h)\right] \\
& =0
\end{aligned}
$$

The price setup described above implies that the bilateral exports price index of the home country, $h$, to the generic country, $C O$ evolves according to:

$$
P_{X, t}^{H, C O}=\left[\xi_{X}\left(\left(\Pi_{X, t-1}^{H, C O}\right)^{\chi_{X}} \bar{\Pi}^{1-\chi_{X}} P_{X, t-1}^{H, C O}\right)^{1-\theta_{T}}+\left(1-\xi_{X}\right)\left(\tilde{P}_{X, t}^{H, C O}\right)^{1-\theta_{T}}\right]^{\frac{1}{1-\theta_{T}}}
$$

\section{Fiscal Policy}

The government in each region adjusts lump-sum taxes to stabilize debt. Governments in regions that impose tariffs to foreign exporters have additional revenues in their budget constraint. Hence, the period-by-period budget constraint of the government in the home country $H$ that imposes tariffs to exporters of country $C O$ receives the following form:

\footnotetext{
${ }^{6}$ I-type households are purely forward looking, have access to all financial and capital markets.
} 


$$
\begin{aligned}
& P_{G}^{H} G_{t}+T R_{t}^{H}+B_{t}^{H}+M_{t-1}^{H}=\sum_{C O \neq H} \tau_{t}^{H, T} P_{X, t}^{C O, H} I M_{t}^{H, C O}+\tau_{t}^{H, C} P_{C, t}^{H} C_{t} \\
& +\left(\tau_{t}^{H, N}+\tau^{H, W_{h}}\right) \frac{1}{s^{H}}\left(\int_{0}^{s^{H}(1-\omega)} W_{t}^{H}(i) N_{t}^{H}(i) d i+\int_{s^{H}(1-\omega)}^{s^{H}} W_{t}^{H}(j) N_{t}^{H}(j) d j\right) \\
& +\tau_{t}^{H, W_{f}} W_{t}^{H} N_{t}^{H}+\tau^{H, K}\left(R_{k, t}^{H} u_{t}^{H}-\left(\Gamma_{u^{H}}\left(u_{t}^{H}\right)+\delta\right) P_{I, t}^{H}\right) K_{t}^{H}+\tau_{t}^{H, D} D_{t}^{H}+T_{t}^{H}+\frac{B_{t+1}^{H}}{R_{t}}+M_{t}^{H}
\end{aligned}
$$

The first term on the RHS in the equation above denotes revenues from import tariffs imposed by country $H$ on exporters from country $C O$. The government rebates the revenues from import tariffs lump-sum to domestic households. As far as what each variable in equation (7) above denotes, we direct the reader to the original paper (see Gomes et al. (2012)).

\section{Results}

In what follows we report the results considering a tit-for-tat US-China trade conflict where the US imposes an across the board 10\% tariff on all Chinese imports. China retaliates after one quarter with a similar tariff on all American exports to China. Tariffs in our model are permanent. We have kept the values for the calibrated parameters for the US and China (RoW) as in Gomes et al. (2012). In their calibration though Germany is considered as the home country, while in our calibration we consider the Netherlands. The trade weights have been obviously adjusted and the data are available upon request. However, we report the euro area wide results as far the latter is concerned. This means that our results for the EA hold regardless of which country is considered to be the home one.

\subsection{Global impact}

Consider first the global impact of a unilateral tariff of the US on Chinese exporters. Figure 1 below shows that the US trade actions have a significantly negative impact on world output, output falls rapidly by $0.2 \%$, a decline that increases to a global output decline of $0.3 \%$ eventually in the medium-run (the solid blue line in figure 1).

Consider now the case of a retaliation from China (black dashed lines). One quarter after US tariffs on Chinese products, China is expected to retaliate and actually does so, also by an across-the-board tariff levied over all imports from the US. In this case, 


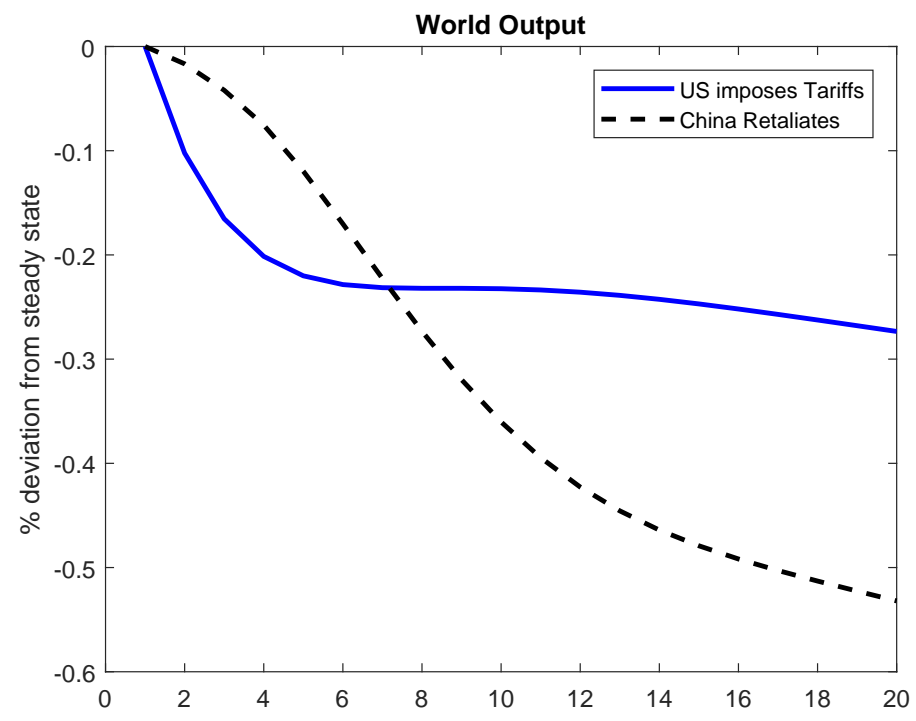

Figure 1: The blue solid lines depict the responses when only the US imposes tariffs on Chinese exporters. The black dashed lines depict the responses when China retaliates.

the contraction in world output is slower initially. The milder drop in output initially is due to the fact that consumers in both regions smooth their consumption less and prefer to consume more today, given the upcoming increase in prices in the future. Recall that price stickiness delays the increase in import prices due to tariffs. However, in the medium-run the contraction in world output is deeper compared to the unilateral US-tariff case. Obviously, the Chinese retaliation leads to a further rise in the prices of internationally traded goods between the two regions which dampens their private consumption further.

\subsection{The impact split by region: the US and China}

In figure 2 we display the responses of key macro variables for the US. Solid lines show the response to the US tariffs against China, the black dashed lines add in Chinese retaliation. First, we discuss the impact of the US tariffs on Chinese exporters only. The most striking result is the decline in GDP in the US itself once it imposes the tariffs on imports from China.

The direct channel is a significant decline in employment as tariffs lead to higher costs of imported intermediates throughout the economy. Although tariffs imply a subsidy to domestic producers, they also imply a tax on all users of imported goods, an effect that dominates the impact on short-run output. Consumption in both variants decline and investment actually slows down. A second mechanism works through the 

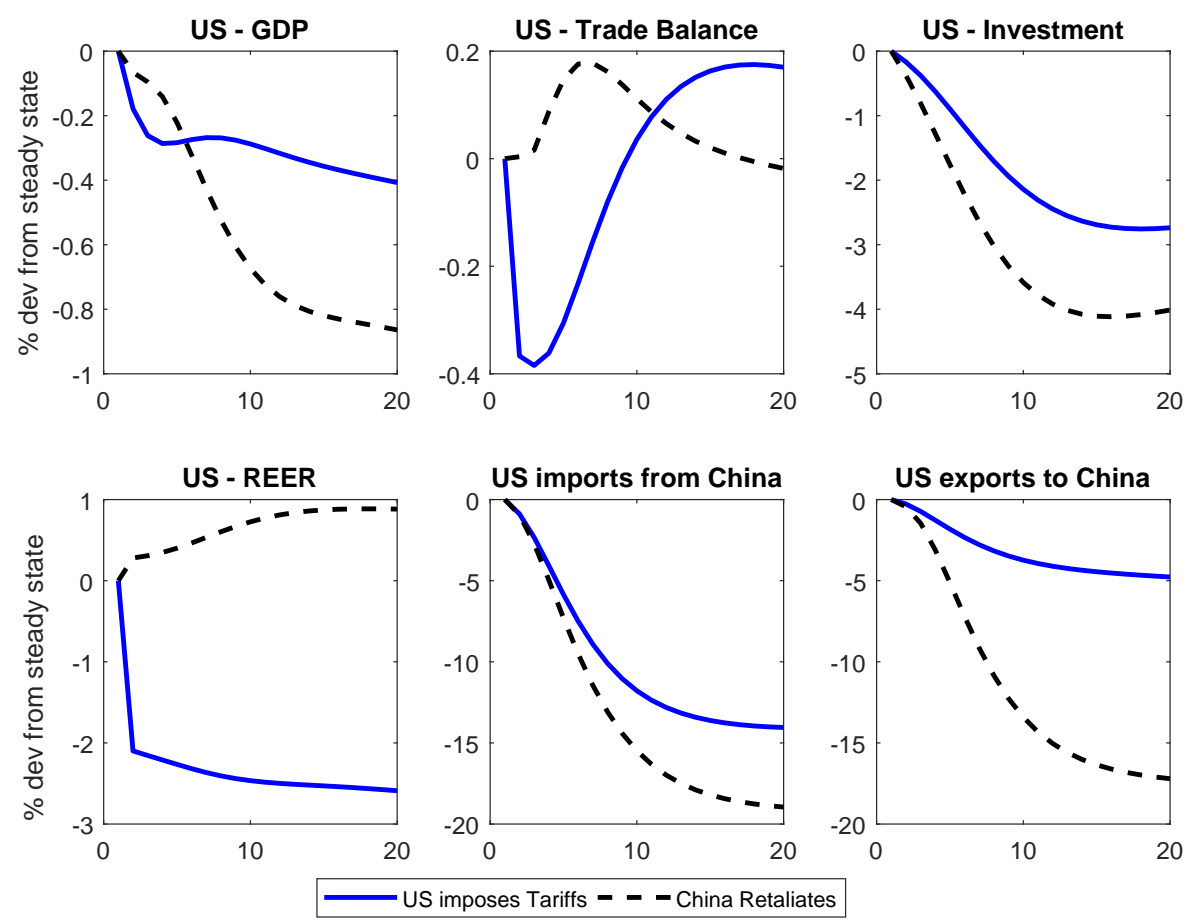

Figure 2: Effects on US. Blue solid lines: only the US imposes tariffs on Chinese exporters. Black dashed lines: China retaliates. An increase in the real effective exchange rate (REER) corresponds to a depreciation. US consumers profit from Chinese retaliation as US domestic producers divert goods previously exported to China to the domestic market. 

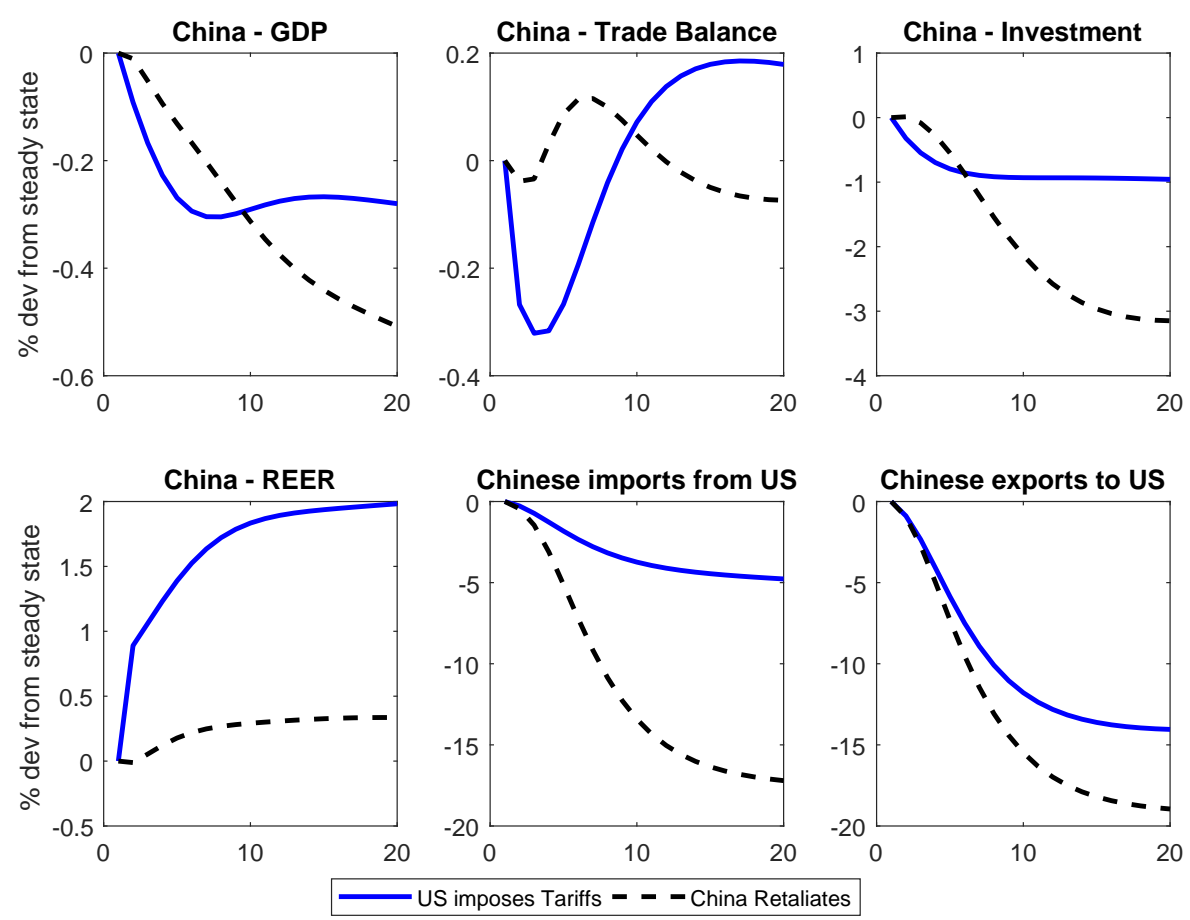

Figure 3: Effects on China. Blue solid lines: only the US imposes tariffs on Chinese exporters. Black dashed lines: China retaliates. An increase in the real effective exchange rate (REER) corresponds to a depreciation.

exchange rate impact. Diverting consumer demand from foreign to domestic goods leads to an exchange rate appreciation that actually undermines exports: the plots show a clear decline in US exports. This is the Lerner symmetry theorem at work: import tariffs are equivalent to export taxes.

We now turn to retaliation from China (black dashed lines). Chinese retaliation adds significant injury to the US. US growth slows down significantly more as do the other macro-indicators. In China similar patterns emerge: a significant slowdown in GDP, investment and consumption expenditure, see figure 3 .

\subsection{The impact split by region: Euro area}

Let us now turn our attention to the euro area. The results show that not everybody loses in this trade war scenario. The EA as a third party actually stands to profit from the trade flow effects of the trade war. We display the effects in the EA in figure 4 When the US levies tariffs (solid blue line), the Chinese face a setback in the US and Chinese exports are diverted to the EA at lower prices as they run into higher tariffs in the US: Chinese pre-tariff prices go down and the EA profits from cheaper (and hence more) imports from China. Lower Chinese prices also affect EA competitiveness in 

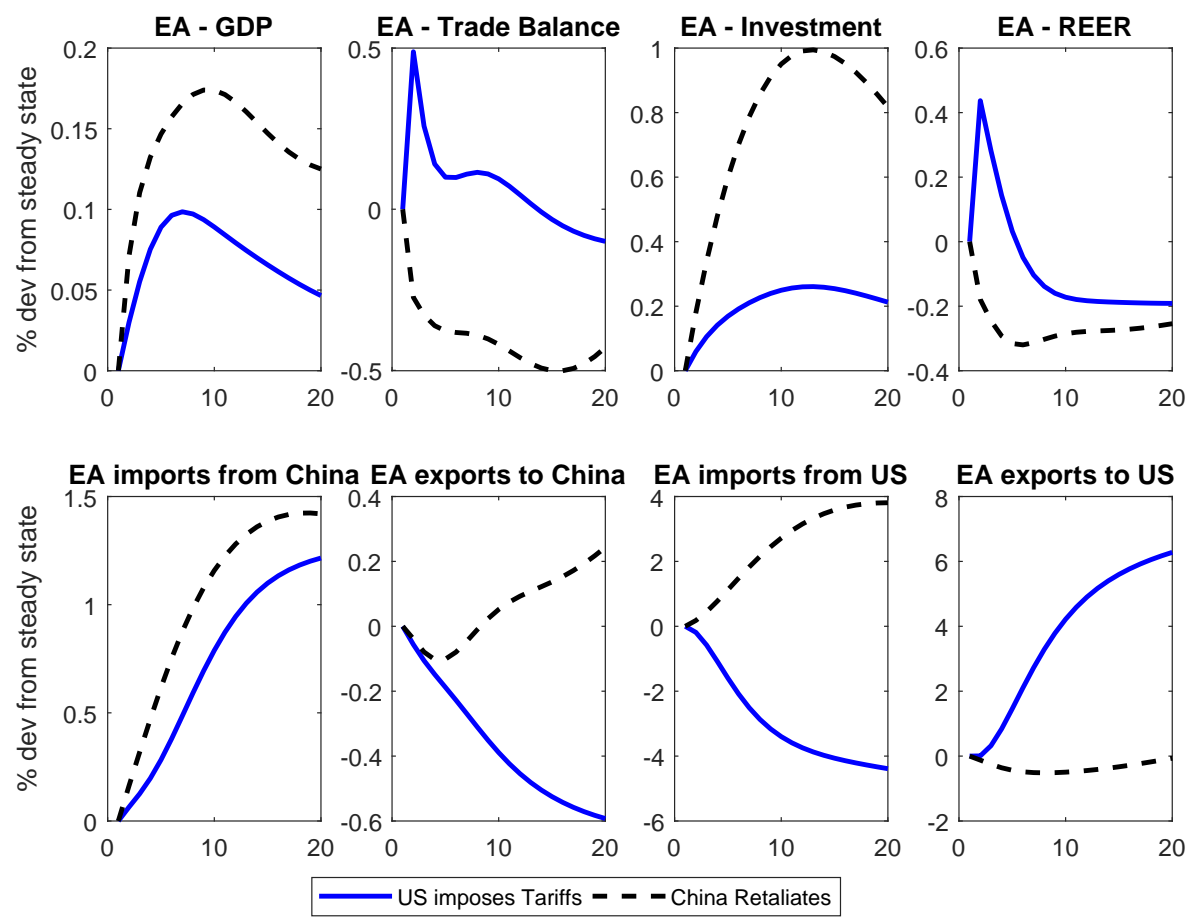

Figure 4: Effects on the euro area. Blue solid lines: only the US imposes tariffs on Chinese exporters. Black dashed lines: China retaliates. An increase in the real effective exchange rate (REER) and the real exchange rate (RER) corresponds to a depreciation.

China negatively, so exports from the EA to China decline.

When China retaliates against the US, the import tariffs put upward pressure on Chinese prices as Chinese demand for US goods is partially diverted to home goods. This allows for a strong resurgence of EA exports to China (black slotted line).

Lerner symmetry effects then explain that EA imports from China go up (further) also; the EA economy was already profiting from the US tariffs against China, exporting more to China is then complemented by importing more, partially from China.

Equally, post-tariff prices of Chinese goods in the US go up, which improves the EA's export competitiveness vis-à-vis Chinese exporters in the US and, because of the appreciation of the dollar, also with respect to domestic US producers. As a consequence EA exports to the US rise also. Imports from the US go down in the US tariff only scenario, as US prices go up after the tariff-induced appreciation of the dollar. Once the Chinese retaliate against the US, EA-US trade patterns change: US pressure on prices declines as exports to China fall, and as a consequence EA imports from the US go up, partially compensating the US for lost exports to China. EA exports to the US fall mildly, as the competitiveness of the EA falls with respect to the US tariffs only scenario for the same reason. The US tariffs against China lead to a mild boom 

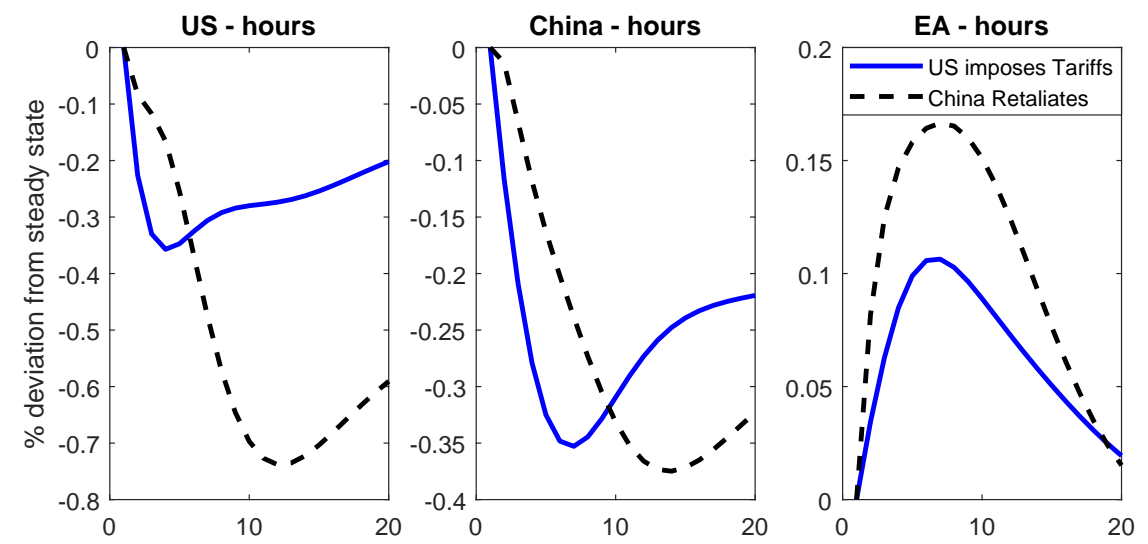

Figure 5: Employment response in the three main regions: Blue solid lines: only the US imposes tariffs on Chinese exporters. Black dashed lines: China retaliates.

in Europe: output rises quickly, an effect that is reinforced by the Chinese retaliation against the US. Investment goes up in line with output, adding demand pressure in Europe initially but allowing for higher output later on. In the retaliation case, the persistent real effective exchange rate appreciation deteriorates the trade balance in the EA, but at the same time improves the purchasing power of households in the EA. This keeps their consumption high which explains partly why output increases more compared to the unilateral US tariffs case.

\subsection{Employment effects, global and by region}

Not surprisingly, given the global output effects shown in section 4.1, the impact on employment is substantial and follows the world output effects closely. We display the responses of employment in figure (5). Instead we want to highlight that the global negative employment effects of the US-China trade war mask considerable regionspecific diversity, as the figure below indicates.

While China and the US hurt each other significantly, European employment actually picks up as exports become more competitive in the US and Chinese imports become cheaper.

\subsection{Intertemporal effects of the trade war: the US trade balance}

Tariffs change relative prices within period, between goods traded at the same time (they concern "intra-temporal trade"), so a priori one should not expect them to have a first order effect on the intertemporal allocation of resources and expenditure, and hence on variables such as the trade balance that arise from differences in the intertemporal pattern of output and of expenditure ("intertemporal trade"). However there are several 
channels that suggest there may be intertemporal effects after all. The first channel is directly macroeconomic: if short term negative income effects are more negative than the long term income effects one should expect intertemporally optimizing consumers to dissave, which would translate in a larger trade (and current account) deficit. Similarly, if investment incentives change, investment may change on a macroeconomic scale, again influencing the short term trade balance. Of course both these effects will only have an impact if they occur asymmetrically across countries, otherwise offsetting global general equilibrium effects will partially or completely offset these partial equilibrium responses. After all, not all countries can lower their trade deficit simultaneously in a global zero trade balance environment.

The second channel comes into play if relative prices change only gradually or even overshoot once the trade war has started because then intertemporal relative prices (i.e. real interest rates) will in fact change and trigger substitution effects in addition to the income effects just mentioned. There are two main factors potentially leading to changes in intertemporal relative prices and from there to trade balance effects: first the tariffs themselves may have an intertemporal effect. We explore on example of that, while the US tariffs are imposed up front and are assumed to be persistent, Chinese retaliation only comes with a one quarter delay, but fully anticipated by assumption. A second channel is more derived: we have incorporated gradual price adjustment of prices in terms of the target country (i.e. exporters practice price discrimination), and that in itself will,even if tariffs are flat over time, generate a changing relative price path over time. In the paper we show that the speed of price adjustment has a substantial impact on the trade balance. We discuss this channel in the following section.

\subsection{Price stickiness and Tariffs}

In this section, we explore the importance of price stickiness in the transmission of tariffs internationally as well as their effects domestically. We consider higher degrees of price stickiness for all exporters in the world. For simplicity, we assume that all exporters have the same Calvo parameter in value. Tariffs, in the model, are imposed on the exporters and not on the final consumer price. Given also pricing-to-market behavior and price stickiness, this means that the pass-through of the tariff to the final price of an exported good is not full. Therefore, price stickiness proves to be one of the key determinants of tariffs incidence. There are of course other factors which also determine the sharing of the tariff burden and which include the elasticity of substitution between home and foreign goods, as well as by the degree of market power determined by the elasticity of substitution across domestic varieties.

However, in this section, we restrict our attention to the effects of different degrees 
of price stickiness. The latter determines the slope of the Phillips curve and as such the extent to which final export prices change following a tariff. In the extreme case of complete price stickiness, $\xi_{X} \rightarrow 1$, the Phillips becomes flat and in this case the exporters bear all the burden of the tariff. We simulate the model again by varying the Calvo parameter, $\xi_{X}$, in the exporter's optimal pricing equation. We conduct our experiments under the case of retaliation from China. Figure 6 displays world GDP for different degrees of price stickiness. To gain further insight consider the log-linearized producer price inflation for exported goods derived by the optimal pricing equation of the exporting firm and from the definition of Calvo pricing.

$$
\pi_{X, t}^{H, C O} \approx \beta E_{t} \pi_{X, t+1}^{H, C O}+\frac{\left(1-\xi_{X}\right)\left(1-\xi_{X} \beta\right)}{\xi_{X} \lambda}\left(\hat{\tau}_{t}^{C O, T}+\hat{s h_{t}^{H}}+\hat{m} c_{t}^{H}\right)
$$

where for the sake of exposition we have assumed zero indexation to past inflation $\left(\chi_{X}=0\right)$, equal degrees of price stickiness in the two regions, $H$ and $C O$, and zero inflation steady state to abstract from price dispersion up to first order. The variable $\hat{s h}_{t}^{H}$ denotes deviations from the law of one price, given local currency pricing, while parameter $\lambda$ is a nonlinear function increasing in deep parameters like trade elasticity and the inverse of the Frisch elasticity of labor supply. From equation (8), it is evident that the extent to which a tariff is transmitted to the final price inflation, $\pi_{X, t}^{H, C O}$ depends crucially on the degree of price stickiness, $\xi_{X}$. Clearly, the higher the $\xi_{X}$ the flatter the Phillips curve and the lower the pass-through of the tariff onto export prices.

Higher price stickiness mitigates the effects of tariffs on world output. When exporters change their prices less frequently, they bear more of the tariff burden. Consumers instead are harmed less from tariffs when stickiness increases. The milder drop in demand in US and China offsets the increasing costs from tariffs due to higher price stickiness. This also fuels a delayed and milder drop in world GDP. We display private total consumption in figure 7 .

Finally, we look at the effects on the rest of key macro aggregates in each region. In figure 8 we plot the impulse responses of output, investment, trade to GDP and the real effective exchange rate in each of the three regions. As mentioned above, for higher degrees of price stickiness the milder contraction in output in the US and China seems to drive the milder drop in world output, given that now the short-run benefits in terms of output in the EA are weaker. Investment also drops less in the US and China when prices are more sticky, a pattern that, we believe, is attributed to the milder drop in consumption demand which delays the drop in firms' output and thereby their demand for capital. The US trade balance as a share of GDP benefits 


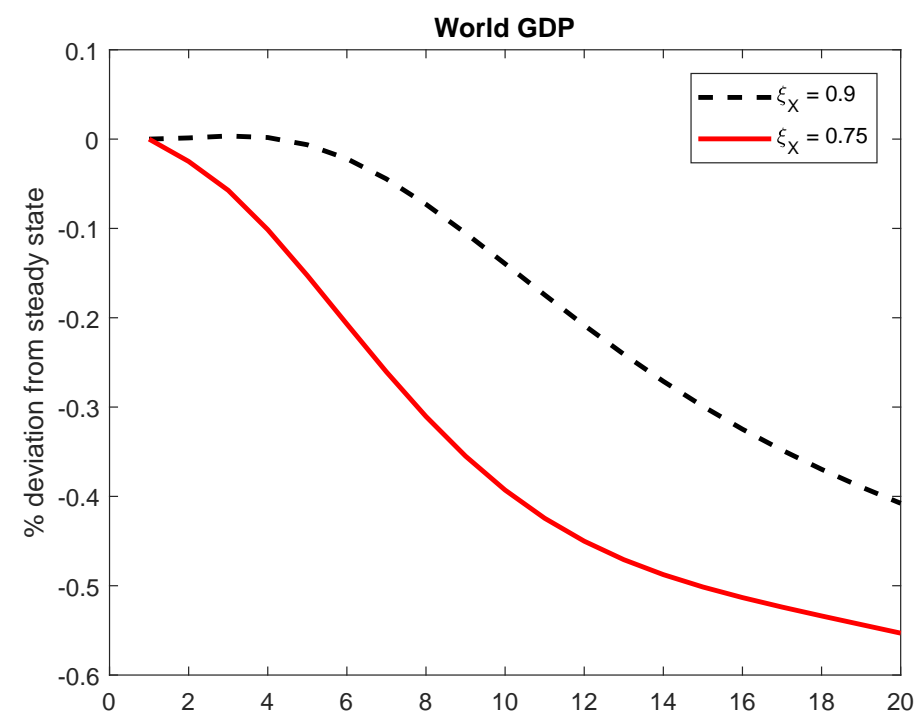

Figure 6: Effects on World GDP.
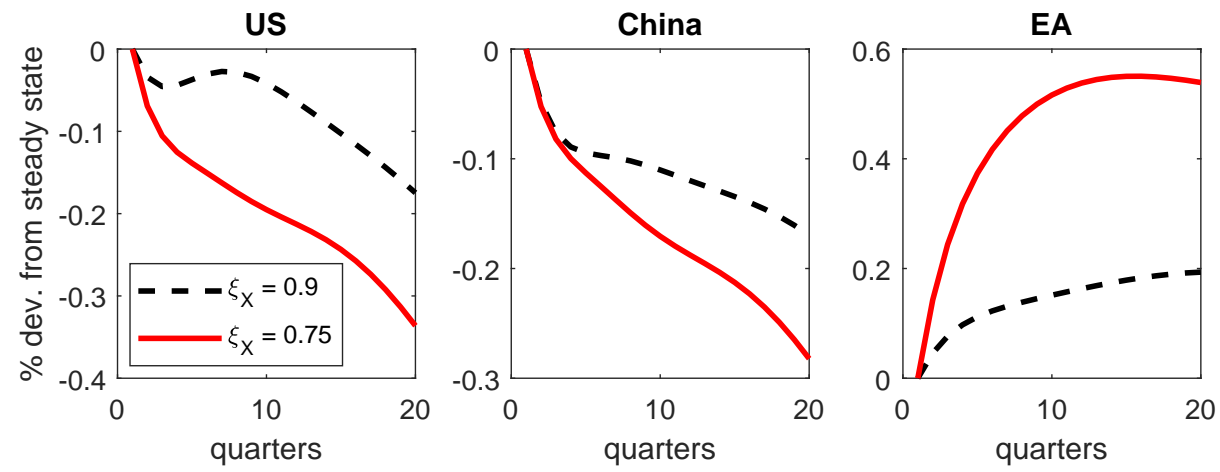

Figure 7: Effects on private total consumption. Private total consumption consists of the sum of the private consumption of Ricardian and non-Ricardian households. 

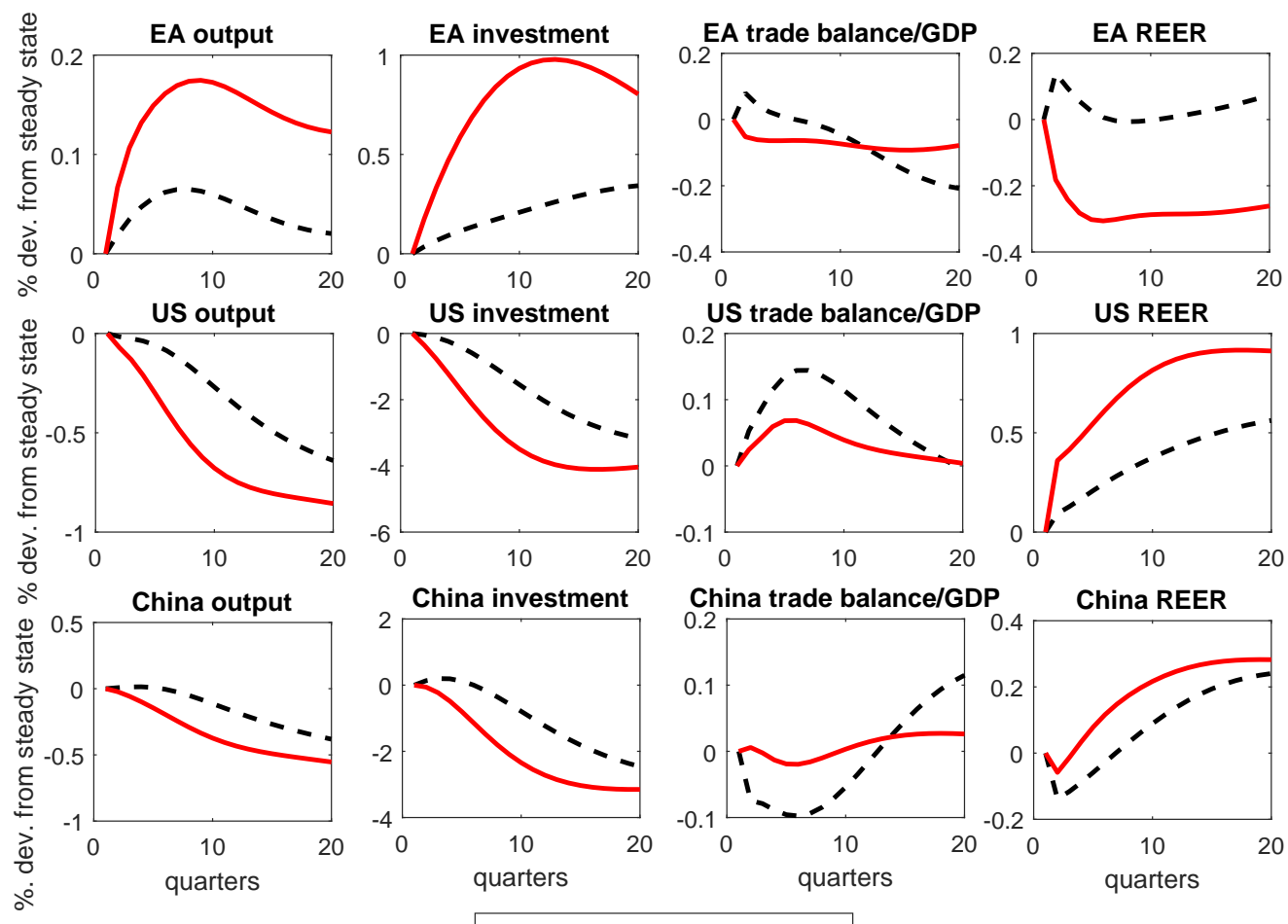

China trade balance/GDP

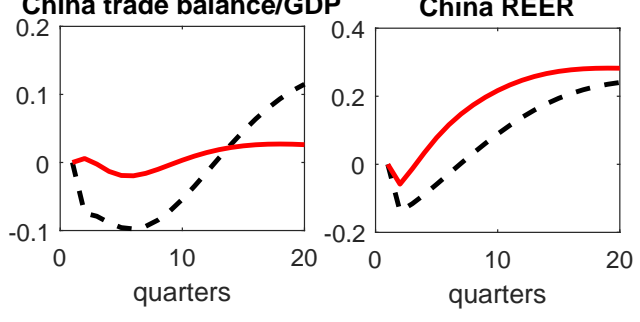

$$
---\xi_{X}=0.9-\xi_{X}=0.75
$$

Figure 8: Effects on output, investment, trade balance to GDP and the real effective exchange rate in the euro area, the US and China, respectively. 
when prices are stickier. Apart from the denominator effects, this is also due to the fact that export prices increase less as fewer US exporters update their prices. This weakens the Lerner-symmetry result and partly offsets the effects due to a weaker REER depreciation. China's trade balance to GDP instead deteriorates when prices are stickier in the short-run. The first reason is the denominator effect. That is, output in China starts to fall with a delay compared to the US. This is because China retaliates one quarter later. This fact along with higher stickiness delay the drop in output and deteriorate the trade to GDP ratio. Apart from the negative effects of tariffs, the latter deteriorates for another reason. The real effective exchange rate of China appreciates more in the first quarters and then starts to depreciate very slowly compared to that of the US and the EA, respectively. However, in the medium-run as the depreciation builds up, the Chinese trade to GDP ratio improves rapidly.

As regards the EA, it seems to benefit less when export prices are more sticky worldwide. The reason is that trade diversion is now lower and as such the increase in private consumption in the EA weaker. Trade diversion is weaker because the relative price of goods imported in the EA changes only mildly due to higher price stickiness. Moreover, the real effective exchange rate depreciates persistently in the medium-run contrary to the persistent medium-run appreciation when prices are less sticky. The persistent depreciation for $\xi_{X}=0.9$ weakens the purchasing power of EA households internationally. This keeps consumption lower than otherwise and hence slows down trade diversion. Therefore, the EA benefits from the trade war between US and China more the less sticky the exporter prices are worldwide.

\subsection{Tariffs and Forward Guidance}

While the tariff war between the US and China is still going on, the EA is lying in a zero lower bound (ZLB) regime. Specifically, since the end of its extended asset purchase program (EAPP) the ECB has not provided any hint of an imminent lift-off of its key policy rate. This policy stance is further supported by the weaker economic data within the monetary union, the US as well as China. In this section, we look at the implications of the ZLB and also of forward guidance (FG) on the EA as well as the rest of the world. We simulate our model assuming that the EA is at the ZLB when US and China impose tariffs on each other. We incorporate FG by assuming that the ECB commits to keeping its policy rate at the ZLB for the first 5 quarters of the simulation. It commits to lift its policy rate from quarter 6 onwards. Agents in our model are fully aware of this commitment which they consider as fully credible. We are aware that our experiment is subject to the FG puzzle. This is why we consider FG 

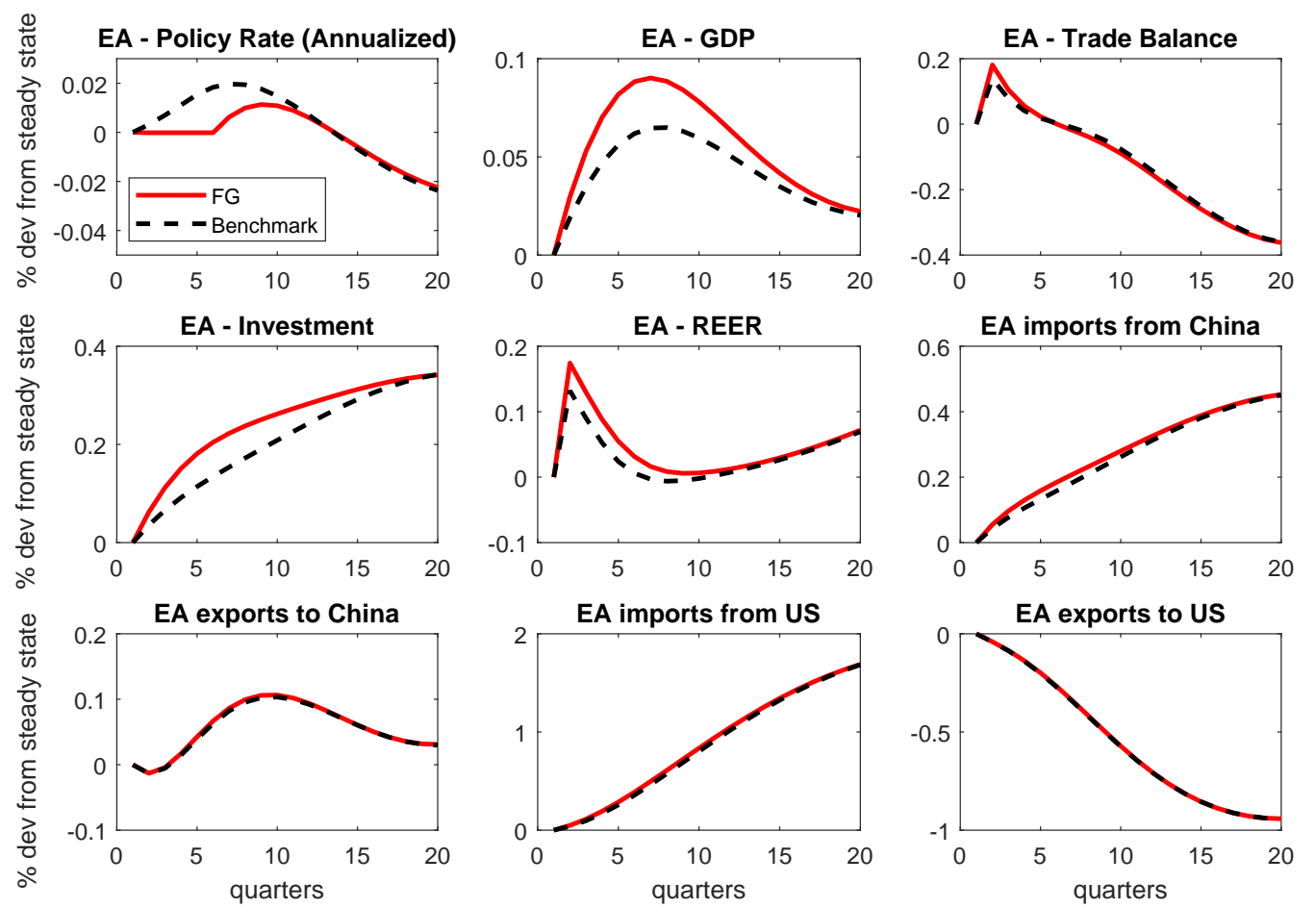

Figure 9: The red solid lines depict the responses in the EA under forward guidance by the ECB. The black dashed lines depict the responses from the benchmark calibration accounting for a retaliation from China. 
up to 5 quarters ahead 17 Nevertheless, our scope is to show that FG on interest rates leads to more pronounced effects in the EA of a tariff war between the US and China.

The ZLB in EA associated with FG leads to marginal changes in the US and China. In the US, the differences with respect to the benchmark calibration without FG are small because of the induced expenditure switching. In particular, US households switch to consume more of domestically produced goods. As a result, domestic demand in the US is now less sensitive to developments in the nominal effective exchange rate as well as to the monetary policy stance of its trade partners. A similar argument holds for China. Given the marginal differences in US and China with respect to the benchmark calibration, we do not display these results in order to save space.

The effects in the EA, displayed in figure (9), are more pronounced when the region is at the ZLB. Output and investment now increase more than in the benchmark calibration. Interestingly, trade diversion from China to the EA increases slightly owing to the stronger increase in demand in the latter. These effects become stronger as the horizon of FG rises 8

\section{Conclusions and further work}

The analysis, stylized as it is, yields some stark conclusions. A trade war leads to global output losses. Even the 10\% tit-for-tat tariff war leads to almost a full percentage less output in the US for several years running and a decline in consumption and investment. The effects on China are similar although slightly milder. In line with economic theory moreover, the import tariff acts like an export tax: US exports decline significantly as their competitiveness is undermined by the dollar appreciation the US measures set off. The euro area profits from cheaper imports from China as they get diverted from the US; and it gains improved competitiveness in the US in response to tariffs against the Chinese and the appreciating dollar. This differential impact also shows in the employment responses: down in the US and China but up in the euro area. But overall the global impact of the US trade actions is negative and more so when the Chinese retaliate: world output declines for years to come.

This paper has focused on the macro impact of various trade policy measures. The specific design of the trade conflict matters for the macroeconomic outcomes. In an extension we could e.g. analyze what happens when the euro area is pulled into the trade conflict between the US and China. Trade diversion benefits will vanish and the global macro effects are likely to be worse. Higher worldwide tariffs change the

\footnotetext{
${ }^{7}$ For a thorough description of the puzzle see Del Negro et al. (2012) and McKay et al. (2016) and the references therein.

${ }^{8}$ The results are available upon request.
} 
allocation of productive resources in the economy, reallocating domestic market share toward less efficient domestic producers, lowering aggregate productivity. It would be useful to analyze the long run effects of restrictive trade measures on potential output in EAGLE.

Further work could usefully focus on the considerable uncertainty and confidence effects generated by the current trade war. Van Wijnbergen (1985, 1992) explores the link between trade policy uncertainty, investment, capital flight and the trade balance in a pure theory setting; but in further work we intend to explore these links quantitatively: how large are the add-on effects of policy generated uncertainty, uncertainty about where this trade war is headed. 


\section{Annex}

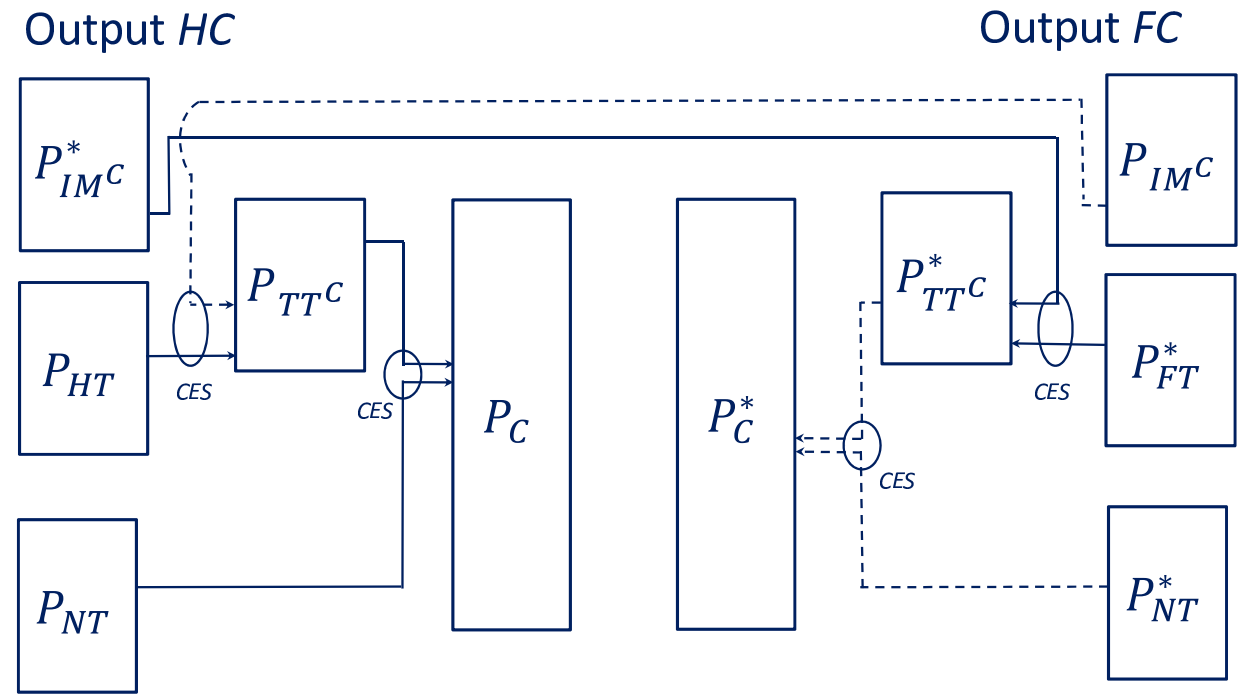

Figure 10: Price - goods flow diagram: A final good in the home country (HC) is a CES 'package' of its domestically non-tradable good and an aggregate tradable good. This aggregate tradable good is a CES 'package' of its domestically intermediate tradable good and an intermediate tradable good produced in the foreign country (FC). 


\section{References}

Bank de France, 2018. Costs and consequences of a trade war: A structural analysis. Policy paper.

Caliendo, L., Parro, F., 2015. Estimates of the trade and welfare effects of NAFTA. Review of Economic Studies 82 (1), 1-44.

Calvo, G. A., 1983. Staggered prices in a utility-maximizing framework. Journal of Monetary Economics 12 (3), 383 - 398.

De Nederlandsche Bank, June 2018. Economic Developments and Outlook. Report 15.

Del Negro, M., Giannoni, M., Patterson, C., 2012. The forward guidance puzzle. Tech. rep.

Department of Labor, 2018. Trade adjustment for workers. Employment and training administration.

ECB, 2018. Macroeconomic implications of increasing protectionism. Economic Bulletin 6.

Erceg, C., Prestipino, A., Raffo, A., 2018. The macroeconomic effects of trade policy. International Finance Discussion papers 1242.

Farhi, E., Gopinath, G., Itskhoki, O., 2014. Fiscal devaluations. Review of Economic Studies 81 (2), 725-760.

Gomes, S., Jacquinot, P., Pisani, M., 2012. The eagle: A model for policy analysis of macroeconomic interdependence in the euro area. Economic Modelling 29 (5), 1686 $-1714$.

Helpman, E., Krugman, P., 1989. Trade Policy and Market Structure. MIT Press.

IMF, October 2018. World Economic Outlook. Report.

IMF, World Bank and WTO, 2017. Making trade an engine of growth for all. Policy paper.

Johnson, H., 1951. Optimum welfare and maximum revenue tariffs. Review of Economic Studies 19 (1), 28-35.

Johnson, H., 1953. Optimum tariffs and retaliation. Review of Economic Studies 21 (2), $142-153$. 
Kutlina-Dimitrova, Z., Lakatos, C., 2017. The global costs of protectionism. Policy Research Working Paper Series 8277, The World Bank.

Lerner, A., 1936. The symmetry between export and import taxes. Economica 3, 306313.

Linde, J., Pescatori, A., 2017. The macroeconomic effects of trade tariffs: Revisiting the lerner symmetry result. CEPR Discussion Papers 12534.

McKay, A., Nakamura, E., Steinsson, J., 2016. The power of forward guidance revisited. American Economic Review 106 (10).

OECD, 2018. Trade policy and the global economy - Scenario 2: Increasing tariffs. Policy brief.

Ossa, R., 2014. Trade wars and trade talks with data. American Economic Review 104 (12), 4104-46.

Van Wijnbergen, S., 1985. Trade reform, aggregate investment and capital flight: On credibility and the value of information. Economic Letters 19, 369-372.

Van Wijnbergen, S., 1987. Tariffs, employment and the current account: Real wage resistance and the macroeconomics of protectionism. International Economic Review 28 (3), 691-706.

Van Wijnbergen, S., 1992. Trade reform, policy uncertainty and the current account: A non-expected utility approach. American Economic Review 82 (3), 626-633.

Van Wijnbergen, S., 2018. On real interest rates, tariff policy, exchange rates and the ZLB. CEPR Discussion Papers 12837. 